\title{
Non-reporting of reportable deaths to the coroner: when in doubt, report
}

Sandra L Neate MB BS, DA(UK), FACEM Consultant Physician

Lyndal C Bugeja BA(Hons), PhD Acting Manager

George A Jelinek MD, DipDHM, FACEM Consultant Physician

Heather M Spoone LLB Coroner

Luke Ding

BCom, LLB Intern

David L Ranson BM BS, LLB, FRCPA Deputy Director

1 Coroners Prevention Unit, Coroners Court of Victoria Melbourne, VIC.

2 Victorian Institute of Forensic Medicine

Melbourne, VIC.

george.jelinek@ coronerscourt.vic.gov.au

MJA 2013; 199: 402-405 doi: 10.5694/mjal3.10246

Editorial p 379 ustralian doctors must report to the coroner deaths that meet the legislative requirements of the Coroners Act relevant to their jurisdiction. In Victoria, the reporting requirements in section 4 of the Coroners Act 2008 (Vic) include deaths that appear unexpected, unnatural or violent or have resulted directly or indirectly from an accident or injury, or are related to a medical procedure. Despite this legal obligation, there is significant underreporting of deaths to the coroner, ${ }^{1}$ and medical practitioners have difficulty recognising reportable deaths. ${ }^{2}$ Nonreporting of reportable deaths limits the ability of the coroners court to fulfil its statutory role in death investigation, particularly in preventing health care-related deaths. ${ }^{3}$

In Victoria, doctors are required to provide a Medical Certificate of Cause of Death (a death certificate) to the Registry of Births, Deaths and Marriages (BDM) for every death that is not reportable to the coroner. A doctor completing a death certificate when the death is reportable to the coroner is potentially in breach of the Act (s 10[1]). BDM clerical staff have long noted possible reportable causes of death on some death certificates, and inaccuracy in describing cause of death. During the 1990s, BDM began to refer deaths to the coroner where it appeared, on the face of the death certificate, that the death was due to traumatic or other unnatural causes. At that time, there was no formal process for medical review of these certificates.

In 2003, a formal process of death certificate referral to the coroner was developed to ensure most of these deaths were identified. BDM began using keywords (eg, fracture, fall, injury, overdose) to trigger a referral. This resulted in a 10 -fold increase in referrals over 2 years; by 2005, some 500 deaths were referred.

\section{Abstrac}

Objective: To better understand the non-reporting of reportable deaths by determining the frequency and nature of reportable deaths referred to the Coroners Court of Victoria (CCOV) by the Registry of Births, Deaths and Marriages (BDM).

Design and setting: Review of referrals from BDM to the CCOV between 2003 and 2011 where an external cause of death was recorded on the death certificate, with detailed review for the period 1 July 2010 to 30 June 2011.

Main outcome measures: Frequency and nature of deaths referred, accuracy of cause of death recorded on death certificate, and degree of change made to cause of death after investigation.

Results: Over 9 years, there were 4283 referrals (annual mean, 476). Of 656 deaths referred between 1 July 2010 and 30 June 2011, 320 (48.8\%) were found to be reportable. Most causes of death related to injuries; less common were choking, deaths after medical procedures, poisoning and transport-related deaths. Most of the deceased were women (55.9\%), were aged $\geqslant 80$ years (80.0\%), and died in hospital (68.4\%). In 309 cases (96.6\%), the coroner changed the cause of death after investigation, with a major change in 146 (45.6\%), minor change in 160 (50.0\%), and deletion of comorbidities in three $(0.9 \%)$. Twenty-one cases $(6.6 \%)$ were investigated further, with one proceeding to an inquest.

Conclusions: Deaths referred by BDM represent a proportion of the unquantified pool of non-reported deaths. Non-reporting of potentially reportable deaths and inaccurate completion of death certificates have significant implications for the health system and community. Further education of medical practitioners about reportable deaths and death certificates is required. Doctors should report any death about which they have doubt.

After BDM referral, a coroner and a Victorian Institute of Forensic Medicine (VIFM) medical practitioner screen the death certificate to determine whether the stated cause of death requires a coroner's investigation. If so, a team of medical reviewers examines the deceased's medical records. As the bodies of people whose deaths are referred by BDM have been buried or cremated and are not available for postmortem examination, the investigation is restricted to medical record review and sometimes collection of witness statements and police reports.

After this medical review, a report indicating probable cause of death is provided to the coroner. The investigation may result in a coronial finding confirming the cause of death on the death certificate or amending the cause to reflect the outcome of the investigation. If concerns relating to health care issues arise, the case may be referred for a standard investigation for deaths involving falls, to the Coroners Prevention Unit (CPU) for further investigation, or for full police investigation. Some cases, although not subsequently legally substantiated, raise the spectre of potential homicide.

To assist medical practitioners' understanding of which deaths must be reported to the coroner, we examined the frequency and nature of reportable deaths referred to the Coroners Court of Victoria (CCOV) by BDM, which were not reported to the coroner by the medical practitioner at the time of death. We also examined the accuracy of completion of death certificates.

\section{Methods}

We conducted a retrospective case series study of deaths referred to the CCOV by BDM between 2003 and 
2011, inclusive, where a coroner determined the death resulted from external causes. We reviewed cases between 1 July 2010 and 30 June 2011 in detail.

\section{Data sources}

From 1 January 2000, data on all referred deaths have been recorded in the CPU's web-based Surveillance Database. Each record contains predefined coded and free-text fields assigned at the death notification stage. Coding is finalised once the coronial investigation is completed. Information for coding is derived from material generated for death certification and the coroner's investigation.

External cause of death was defined based on the World Health Organization classification as "any death that resulted directly or indirectly from environmental events or circumstances that caused injury, poisoning and other adverse events". Deaths were included if the cause of death had an external cause code (V01-Y89) in the International statistical classification of diseases and related health problems, 10th revision (ICD-10). ${ }^{4}$ Deaths were excluded if the coroner determined the death was from natural causes.

\section{Data collection}

For each death meeting the inclusion criteria, 30 variables were recorded in Microsoft Excel, including sociodemographic data, mechanism of death, cause of death recorded on the death certificate, cause of death after investigation, and location of the incident. Data were extracted from the death certificate, medical review of the death, any statements from treating practitioners and the coroner's finding. This material was jointly reviewed and coded by two of us (LD, SLN), and data were exported into SPSS Statistics (IBM) for analysis.

\section{Data analysis}

We compared cause of death recorded on the death certificate with cause of death after investigation, and any changes were deemed major, minor or a simple deletion of comorbidities not relevant to cause of death. There are two parts to cause of death on the death certificate. Part 1 is the disease or condition directly leading to death.

\section{Example of a major change to cause of death}

A: Victorian Medical Certificate of Cause of Death completed by the medical practitioner and submitted to the Registry of Births, Deaths and Marriages (BDM)

PART THREE - Cause of Death

\begin{tabular}{|c|c|c|c|}
\hline \multicolumn{2}{|l|}{15.1} & $\begin{array}{l}\text { Description of disease, } \\
\text { injury or condition }\end{array}$ & $\begin{array}{l}\text { Duration between } \\
\text { onset \& death }\end{array}$ \\
\hline \multirow{2}{*}{$\begin{array}{l}\text { Disease or condition directly leading to death. } \\
\text { Note. Please specify the disease, injury or condition } \\
\text { which led directly to the death not only the mode of } \\
\text { dying such as heart or respiratory failure. }\end{array}$} & \multirow[b]{2}{*}{ a) } & Stroke - ischaemic & 15 days \\
\hline & & & \\
\hline \multirow{4}{*}{$\begin{array}{l}\text { Antecedent causes } \\
\text { Note: If the direct cause of death as described in } \\
\text { line a) was due to, arose as a consequence of } \\
\text { another disease, injury or condition, this should be } \\
\text { reported in line b). Similarly, if the condition on line } \\
\text { b) was due to another condition, report this on line } \\
\text { c) and so forth.. }\end{array}$} & \multirow{2}{*}{ b) } & & \\
\hline & & & \\
\hline & c) & & \\
\hline & d) & & \\
\hline \multicolumn{2}{|l|}{15.2} & $\begin{array}{l}\text { Description of disease, } \\
\text { injury or condition }\end{array}$ & $\begin{array}{l}\text { Duration between } \\
\text { onset \& death }\end{array}$ \\
\hline \multirow{2}{*}{$\begin{array}{l}\text { Other significant conditions } \\
\text { Note: Provide details of any other significant } \\
\text { condition(s) contributing to the death but not } \\
\text { related to the disease, injury or condition causing it. }\end{array}$} & \multirow[b]{2}{*}{ e) } & Subdural haematoma & 13 days \\
\hline & & & \\
\hline
\end{tabular}

The death certificate shows the cause of death assigned by the medical practitioner as natural causes from a stroke 15 days earlier. A subdural haematoma that occurred 13 days before death was assigned as a contributing cause. The recording of "subdural haematoma" prompted BDM to refer the death to the coroner.

Investigation found that the deceased had a stroke 15 days before death, resulting in facial paralysis, and had been admitted to hospital. Two days later, he fell in hospital and sustained a head injury. A computed tomography scan showed a significant subdural haematoma, which was treated conservatively. His conscious state did not improve, and he died 13 days after the head injury. On the basis of this information, the subdural haematoma resulting from the fall was determined to be the cause of death, and the stroke was thought to be a contributing factor. An alternative cause of death was provided to the coroner.

B: The review checklist completed by the consultant physician and forensic pathologist for the coroner

\begin{tabular}{|l|l|}
\hline \multicolumn{2}{|l|}{ CAUSE OF DEATH } \\
\hline 1 (a) & Subdural haematoma from a fall in the setting of a recent stroke. \\
\hline 1 (b) & \\
\hline 1 (c) & \\
\hline 1 (d) & \\
\hline 2 & \\
\hline
\end{tabular}

Based on the medical review, the coroner completed a finding and determined the cause of death as "subdural haematoma from a fall in the setting of a recent stroke".

Part 2 comprises conditions contributing to the death but not related to the disease, injury or illness causing death. We defined a major change as the condition in Part 1 being moved to Part 2 or vice versa, or a new disease or condition not previously recorded being included in Part 1 (Box 1). A minor change was a change in wording or ordering of conditions in Part 1 or the addition of a mechanism of injury (example in Appendix 1; online at mja.com.au). A deletion was removal of comorbidities (Appendix 2; online at mja.com.au).

This study was approved by the Victorian Department of Justice Human Research Ethics Committee.

\section{Results}

Between 2003 and 2011 inclusive, BDM referred 4283 deaths to the CCOV. The mean annual frequency was 476 referrals, ranging from 143 in 2003 to 793 in 2008.

Of 656 deaths referred between 1 July 2010 and 30 June 2011, 320 external cause deaths $(48.8 \%)$ were found to be reportable after investigation.

\section{Reasons for BDM referral to the CCOV}

Nearly all deaths resulted from trauma (Box 2). The three main injuries or complications were fracture complicated by pneumonia, fracture only, and head injury. Of the 190 fracturerelated deaths, 142 (74.7\%) involved fracture of the femur (including neck of femur) or pelvis. Rib fractures leading to pneumonia were also common. Of the deaths involving head injuries, $81(76.4 \%)$ were from subdural haematomas. Non-trauma-related causes of death were choking, intentional and unintentional poisoning, and transport-related incidents; several deaths 
2 Reasons for BDM referral of deaths to Coroners Court of Victoria, July 2010 - June 2011

\begin{tabular}{lc} 
Cause of death & Number (\%) \\
\hline Fall & \\
Causing fracture complicated by pneumonia & $98(30.6 \%)$ \\
Causing fracture & $92(28.8 \%)$ \\
Causing head injury & $83(25.9 \%)$ \\
Causing head injury complicated by pneumonia & $23(7.2 \%)$ \\
Complicated by pneumonia & $6(1.9 \%)$ \\
With other complication & $5(1.6 \%)$ \\
Falls subtotal & $307(95.9 \%)$ \\
Choking & \\
Choking & $4(1.3 \%)$ \\
Choking complicated by pneumonia & $1(0.3 \%)$ \\
Choking subtotal & $5(1.6 \%)$ \\
Medical and surgical care & $3(0.9 \%)$ \\
Transport & \\
Causing head injury complicated by pneumonia & $1(0.3 \%)$ \\
Complicated by pneumonia & $1(0.3 \%)$ \\
Transport subtotal & $2(0.6 \%)$ \\
Animate mechanical forces & $1(0.3 \%)$ \\
Poisoning - pneumonia & $1(0.3 \%)$ \\
Sequelae - pneumonia and head injury & $1(0.3 \%)$ \\
Suicide - poisoning & $1(0.3 \%)$ \\
Total & $320(100 \%)$ \\
\hline &
\end{tabular}

$\mathrm{BDM}=$ Registry of Births, Deaths and Marriages.

had medical procedures recorded in the cause of death field.

\section{Demographic characteristics}

Just over half of the deceased (179, $55.9 \%$ ) were women (Box 3). For both men and women, the highestfrequency age group was 80-89 years. Most deaths occurred in hospitals $(219,68.4 \%)$ and in metropolitan Melbourne (221, 69.1\%). Almost half $(158,49.4 \%)$ occurred in Melbournebased public and private hospitals. In regional Victoria, deaths were evenly distributed among the major regions.

\section{Changes to cause of death after medical review}

In just under half of deaths, a major change to the cause of death was made after medical review (Box 4). Only 10 causes of death $(3.1 \%)$ were not amended. In 309 cases (96.6\%), the coroner directed a change to the cause of death to more accurately reflect the condition causing death, the time sequence and causative connection between the listed conditions, the mechanism of injury (eg, fracture sustained in a fall), or any contributing factors (eg, subdural haematoma in the setting of anticoagulation).

3 Deaths referred by BDM to Coroners Court of Victoria, July 2010 - June 2011, by age group and sex of the deceased

\begin{tabular}{lccc} 
Age group (years) & Men & Women & Total \\
\hline $30-39$ & - & $1(0.6 \%)$ & $1(0.3 \%)$ \\
$40-49$ & $1(0.7 \%)$ & $1(0.6 \%)$ & $2(0.6 \%)$ \\
$50-59$ & $2(1.4 \%)$ & $4(2.2 \%)$ & $6(1.9 \%)$ \\
$60-69$ & $14(9.9 \%)$ & $2(1.1 \%)$ & $16(5.0 \%)$ \\
$70-79$ & $19(13.5 \%)$ & $15(8.4 \%)$ & $34(10.6 \%)$ \\
$80-89$ & $64(45.4 \%)$ & $79(44.1 \%)$ & $143(44.7 \%)$ \\
$90-99$ & $38(27.0 \%)$ & $73(40.8 \%)$ & $111(34.7 \%)$ \\
$\geqslant 100$ & - & $2(1.1 \%)$ & $2(0.6 \%)$ \\
Unknown & $3(2.1 \%)$ & $2(1.1 \%)$ & $5(1.6 \%)$ \\
Total & $141(100 \%)$ & $179(100 \%)$ & $320(100 \%)$ \\
\hline BDM = Registry of Births, Deaths and Marriages. & &
\end{tabular}

4 Frequency and nature of changes to cause of death in death certificates referred by BDM to Coroners Court of Victoria, July 2010 - June 2011

Outcome

Number (\%)

$\begin{array}{lc}\text { Major change only } & 35(10.9 \%) \\ \text { Major change AND removal of comorbidities } & 11(34.7 \%) \\ \text { Major change subtotal } & 146(45.6 \%) \\ \text { Minor change only } & 65(20.3 \%) \\ \text { Minor change AND removal of comorbidities } & 95(29.7 \%) \\ \text { Minor change subtotal } & 160(50.0 \%) \\ \text { Removal of comorbidities only } & 3(0.9 \%) \\ \text { No change } & 10(3.1 \%) \\ \text { Not applicable - open case } & 1(0.3 \%) \\ \text { Total } & 320(100 \%)\end{array}$

$\mathrm{BDM}=$ Registry of Births, Deaths and Marriages.

\section{Further investigation}

In 21 cases $(6.6 \%)$, the coroner directed that further investigation be undertaken. This comprised:

- request for further witness statements from medical, nursing and administrative personnel regarding medical management or other investigation $(n=13)$

- request to residential aged care facilities to provide policies and protocols on falls prevention and management $(n=4)$

- referral to the CPU's Health and Medical Investigation Team for extensive review of health care provided $(n=4)$.

With this additional information, the coroner completed the investigations without inquest. One investigation revealed matters requiring an inquest.

\section{Discussion}

Formal surveillance of death certificates by a BDM registry and expert medical review of referred deaths is unusual, and most medical practitioners would be unaware of it. In Vic- toria, this process identifies part of the unquantified pool of non-reported reportable deaths and enables the investigation of deaths that would otherwise have gone unreported. Our data underreport the problem as they examine only one form of reportable death (external causes) and only those deaths referred when BDM staff were alerted by the wording on the death certificate.

In our analysis, most non-reported deaths involved trauma resulting in fractures or head injuries that immediately or subsequently caused or contributed to the death. Other less common external causes of death were choking (on food bolus), poisoning (including suicide) and transport crashes. Most deaths involved very old people in hospitals in Melbourne. Nearly $7 \%$ of the deaths required investigation beyond that performed by the VIFM medical reviewers, with one proceeding to inquest.

An inquest into a non-reported death caused by an unintentional heroin overdose was held in the CCOV in 


\section{Possible reasons for doctors' non-reporting of reportable deaths}

Difficulty in understanding their statutory obligations, possibly due to differing medical and legal interpretations of terms such as "unexpected" or "unnatural" death

- Communication problems between doctors and Court staff when doctors attempt to report a death or obtain advice about whether a death is reportable

- Difficulty in understanding the causal connection between trauma and the death, particularly when events are separated in time (eg, traumatic spinal or brain injuries or fractures may cause death a long time after the injury). Together with factors including prolonged care, transfer between facilities and involvement of multiple medical practitioners over time, this may result in the reportability of the death, as related to the original injury, not being considered

- Difficulty determining whether deaths related to medical procedures are reportable

- The potential for junior doctors who correctly believe that a death is reportable to be advised otherwise by senior medical colleagues

- Misconceptions that deaths are only reportable when they are "suspicious". Practitioners may recognise that injury has contributed to death but because the death is not suspicious, they believe the death is not reportable

Misconceptions that families' objections to autopsy should be considered before reporting

2012 to highlight this problem. ${ }^{5}$ During the inquest, evidence was given about possible reasons for doctors' non-reporting of reportable deaths (summarised in Box 5). Ignorance and misunderstanding of the reporting requirements of the Act appear to lie behind many failures to report deaths to the coroner.

Our analysis also examined the accuracy of death certificate completion. The death certificate is a record of the disease or condition causing death. After investigation, nearly 50\% of cases required a major change to the stated cause of death, indicating a high frequency of inaccurate death certificate completion. Only 3\% of certificates did not require alteration. The major problems included:

- Listing mode of death (eg, multiorgan failure, cardiac arrest) rather than a pathological condition (eg, pneumonia, myocardial infarction, dementia) as cause of death

- Failure to list conditions in a logical causative sequence

- Problems determining whether a condition caused or contributed to the death

- Inclusion of conditions unrelated to the death (eg, "glass eye" listed in Part 2). Death certificates should not include all comorbidities, just the causative disease.
Inaccurate completion of death certificates may result in poor understanding by the deceased's family of the cause of death, initiation of unsupportable civil claims, unnecessary investigation of deaths, or prevention of a death investigation. It may also affect the accuracy of mortality data.

Since the 2012 inquest, ${ }^{5}$ the CCOV has attempted to overcome communication problems between the Court and medical practitioners when they are reporting a death. Coronial recommendations arising from the inquest included that health services should ensure medical practitioners are appropriately educated and made aware of their legal obligations, and that hospitals should develop a system of senior medical peer review of the cause of death before submission to BDM. The Australian Health Practitioner Regulation Agency has responded ${ }^{6}$ by preparing an educational article for all registered medical practitioners in Australia.?

Non-reporting of reportable deaths precludes the possibility of complete and thorough investigation into the circumstances and cause of death, particularly where an autopsy could have resolved key questions regarding the manner of death. Detailed death investigations can provide vital information to the family, treating practitioners and the coroner regarding not only cause of death, but also potentially preventable aspects of the death. This information is important to the health system and the wider community as it underpins patient management, risk management systems and disease prevention strategies. Problems with accurate completion of death certificates and public health aspects of the non-reporting of reportable deaths may be partly overcome by further education of medical practitioners.

Finally, a death does not have to be reportable to be reported to the coroner, as the determination of reportability can sometimes only be made after investigation by the Court. Doctors are best protected by reporting any deaths about which they have doubt.

Competing interests: Heather Spooner is the coroner who made the relevant findings in the 2012 inquest discussed in this article.

Received 26 Feb 2013, accepted 29 May 2013.

1 Charles A, Ranson D, Bohensky M, Ibrahim JE. Under-reporting of deaths to the coroner by doctors: a retrospective review of deaths in two hospitals in Melbourne, Australia. Int J Oual Health Care 2007; 19: 232-236.

2 Start RD, Delargy-Aziz Y, Dorries CP, et al. Clinicians and the coronial system: ability of clinicians to recognise reportable deaths. BMJ 1993; 306: 1038-1041.

3 Ibrahim JE, Ranson DL, O'Brien A, et al. Forensic investigation of medical treatment related deaths. Leg Med (Tokyo) 2009; 11 Suppl 1: S71-S75.

4 World Health Organization. International statistical classification of diseases and related health problems, 10th revision (ICD-10). Chapter $X X$ : External causes of morbidity and mortality. Geneva: WHO, 2010.

5 Coroners Court of Victoria. Finding: inquest into the death of Fikri Memedovski. Melbourne: CCOV, 2012. http://www.coronerscourt.vic.gov.au/ home/coroners+written+findings/findings++inquest+into+the+death+of+fikri+memedov ski (accessed Feb 2013).

6 Flynn J; Medical Board of Australia. Response: Investigation into the death of Fikri Memedovski. Melbourne: MBA, 2013. http://www.coroners court.vic.gov.au/resources/77f07c52-d727-4479a028-b350dc3f9bb8/responsemedicalboard aust_memedovski.pdf (accessed Feb 2013).

7 Medical Board of Australia. From the coroner. Update 2013; (6): 3. http://www.medicalboard. gov.au/News/Newsletters/June-2013.aspx (accessed Aug 2013) 